\title{
Improving standards of nutritional care on a cancer ward: the development and evaluation of a nutritional care assistant role
}

This article was published in the following Dove Press journal:

Clinical Audit

29 June 2010

Number of times this article has been viewed

\section{Mary Wells' \\ Fiona Ross ${ }^{2}$ \\ Jackie Davie ${ }^{3}$ \\ Thilo Kroll'}

'School of Nursing and Midwifery, University of Dundee, Dundee, Scotland, UK; ${ }^{2}$ Department of Nutrition and Dietetics, Torbay Hospital, Torquay, UK; ${ }^{3}$ Tayside Cancer Centre, Ninewells Hospital and Medical School, Dundee, Scotland, UK

Correspondence: Mary Wells School of Nursing and Midwifery, University of Dundee, Dundee, Scotland, UK DDI 4HJ

Tel +44 I 382388643

Fax +44 I 382388533

Email e.m.wells@dundee.ac.uk
Purpose: Patients with cancer are particularly at risk of malnutrition and suffer a range of nutritional problems as a consequence of their disease and its treatment. Clinical outcomes may be adversely affected and the normal, pleasurable, and social aspects of eating and drinking are often lost within a busy hospital ward environment. This project aimed at developing and evaluating a role for a nutritional care assistant (NCA) over 22 months to improve standards of nutritional care on a cancer ward, through systematic nutritional assessment, attention to the physical and social factors that promote good nutrition, and the provision of healthy and nutritious snacks.

Patients and methods: Evaluation measures included snapshot audits of nutritional screening, patient questionnaires to assess views of eating and drinking, process audit of the contribution made by the NCA, and staff knowledge and attitude questionnaires. 277 cancer patients were seen by the NCA.

Results: Feedback from patients and staff showed that the project had a positive impact on the provision of food and drink and the experience of patients on the ward. Nutritional screening and documentation also improved.

Conclusion: The findings of this audit demonstrate that simple and innovative changes at ward level can make a tangible difference to standards of nutritional care, and to patients' experiences of eating and drinking, even in the context of cancer.

Keywords: malnutrition, hospital, environment, nutritional assessment

\section{Introduction}

Approximately $40 \%$ of hospitalized patients suffer from malnutrition. ${ }^{1}$ Patients with cancer are particularly at risk; indeed it is estimated that up to $85 \%$ experience weight loss and/or anorexia ${ }^{2,3}$ with significant effects on quality of life. ${ }^{4}$ Cancer treatments including surgery, radiotherapy, and chemotherapy can have serious adverse effects on nutritional intake, by interfering with patients' ability to taste, swallow, or digest food. The normal, pleasurable, aspects of eating and drinking are often lost.

There is good evidence that malnutrition is associated with worse clinical outcomes, including poorer response to treatment and shorter survival. ${ }^{5-7}$ Within this context, the findings of several recent reports are particularly worrying. Consistent evidence shows that nutritional intake in hospitals is poor, and that basic aspects of nutritional care are often neglected. ${ }^{8-10}$ Food wastage is also a significant problem. ${ }^{11}$

In an increasingly high-tech care environment, nursing staff may pay insufficient attention to basic aspects of eating and drinking. Specialist input from dietitians is at a premium, so there is a danger of nutritional care falling into a 'care gap' ${ }^{12}$ If 
nutritional needs are not identified and addressed, there may be significant costs for the individual and for the healthcare system. ${ }^{13}$

Nutritional care in the in-patient oncology setting is affected by a complex range of physical and social factors. ${ }^{14}$ Early identification and intervention for patients who are malnourished is vital. ${ }^{15}$ The introduction of a nutrition screening tool has been shown to improve assessment and awareness amongst nursing staff. ${ }^{12}$ Studies have also demonstrated that it is possible to increase energy and protein intakes by offering fortified meals and snacks to hospitalized patients. ${ }^{16,17}$

This project aimed at developing a role for a nutritional care assistant (NCA) to improve standards of nutritional care on a cancer ward. Specific objectives were -

1. To improve the detection of nutritional problems on an oncology ward, through the introduction of a more systematic approach to nutritional screening

2. To provide healthy and nutritious snacks and drinks, in between meals, for all patients with cancer on the ward

3. To improve patients' experiences of eating and drinking

4. To enhance the knowledge, skills and awareness of ward staff towards nutritional care

The project commenced soon after the publication of the Clinical Standards for Food, Fluid and Nutritional Care in Hospitals, ${ }^{18}$ and was able to adapt to, and address, many of these standards in practice. The project took place on a 32-bed oncology ward within a large teaching National Health Service (NHS) hospital in the Tayside area of Scotland. A NCA was employed for 26 months, and her role was evaluated as part of a Big Lottery funded grant. The main responsibilities of the NCA are detailed in Box 1. The NCA had previously worked as a cook and care assistant in a social care facility. She was provided with a three-month induction and training period, working closely with a dietitian for one-toone supervision and training, as well as undertaking short vocational courses on food handling, infection control, and nutritional care.

\section{Materials and methods}

Following the induction and training period, the NCA provided a consistent service for 22 months, supported by other Health care assistants on the ward. Policies and agreements were set up with the diet kitchen, supplies department, infection control department, health and safety advisers, and external food suppliers so as to ensure that appropriate snacks and drinks were produced at ward level
Box I The key responsibilities of the nutritional care assistant

- To assess patients' nutritional status on admission to the ward, using an agreed nutritional screening tool.

- To refer patients to dietitian if malnourished or at risk, and ensure that individualized nutritional care plans are implemented and followed.

- To assess and document patients' food preferences and specific needs, ensuring that other ward staff are aware of these.

- To assist patients with appropriate food choices from hospital menus, according to their nutritional needs.

- To co-ordinate the provision of nourishing snacks and drinks between meals as appropriate for patients' needs, including a daily fresh smoothie and fruit salad "round" (see Figure 3) and individualized snacks as needed.

- To assist with the serving of meals to ensure that suitable portions of appropriate foods are presented attractively to patients.

- To provide basic written and verbal information to patients and carers on aspects of food choice and nutrition, as appropriate to their needs and consistent with advice from dietitians.

- To support the development and provision of nutrition workshops at the Maggie's Centre (Cancer Caring Centre adjacent to the hospital, where people affected by cancer can obtain information and support).

as cost effectively as possible and within all existing food storage and preparation guidelines. Information resources for patients and carers were also produced, including a recipe leaflet for nutritious smoothies. Copies of CancerBackup booklets and patient nutrition information leaflets were obtained, to be given out under the supervision of the project dietitian.

Process evaluation data were collected on the number and characteristics of patients who were provided with individualized nutritional care and support by the NCA over the duration of the project. Any changes to the provision of the food and drink service were documented, and observations of care at mealtimes were also recorded.

\section{Evaluation tools}

Outcome evaluation data were collected at baseline, interim (one year into the project) and at completion of the project. A range of outcomes were assessed via short questionnaires, for the following indicators:

\section{Nutritional screening procedures on the ward}

A 4th year student dietitian undertaking a final year research project carried out snapshot audits of inpatient nursing notes at baseline, and at the end of project, to assess how thoroughly patients on the ward were being screened for nutritional problems by nursing staff. The audit included whether or not the following items were documented: weight, height, BMI (body mass index), percentage weight change, supplements or consistency altered diet, current intake, preferences, 
and specific dietary needs. It was also noted whether a nutritional screening tool had or had not been used. When the project started, MUST (Malnutrition Universal Screening Tool) had not yet been introduced, so the audit assessed whether or not any nutritional screening tool was used.

\section{Patients' views about eating, drinking and perceived benefits of extra snacks and drinks}

An eating and drinking questionnaire, with a number of questions about food choice, environment, and nutritional support, was administered to patients on the ward over a 2-week period at baseline, interim and at the end of the project. This questionnaire was developed specifically for the project, with reference to existing tools ${ }^{19}$ which were not felt to be ideally suited to patients experiences of food and drink in an inpatient setting. Patients were asked to rate from a list of 12 items, which symptoms or problems most interfered with their eating and drinking on the ward (see Figure 1 for item details). This questionnaire also used Likert scale statements, asking respondents to indicate whether they strongly disagree/disagree/neither agree or disagree/agree/strongly agree (see examples of Likert questions in Table 2, column 1). Some open-ended questions were also included. Patients' views of the fruit, snacks and smoothies provided on the ward were assessed using a short questionnaire, given to all patients on the ward, over a period of a month during the second year of the project. Patients were asked whether they had been offered snacks, fruit and smoothies, whether they would try these again at home, what difference they had made to the hospital stay, and for any other comments about the food and drink provided on the ward, in particular the NCA service.
The knowledge and skills of ward nurses towards nutritional care

A staff nutrition questionnaire was developed by the project dietitian and project coordinator. Questionnaire items were designed to assess staff knowledge of key facts related to nutritional assessment and common nutritional problems in patients with cancer. Some items provided a short scenario for which staff were asked to select the most appropriate nutritional care option eg, for a patient a) undergoing pelvic radiotherapy b) with swallowing difficulties c) weight loss during chemotherapy.

Over a 4-week period at baseline, and at the end of the project, all staff on the ward were invited to complete the questionnaire. Responses were anonymous but color coded so that it was possible to determine whether they had been completed by a qualified staff nurse or a health care assistant. At the end of the project, they were asked to comment on what aspects of food and drink they thought had improved as a result.

\section{Data analysis}

All quantitative data were entered into SPSS (Statistical Package for Social Sciences) Version 12. Data were analyzed using descriptive and non-parametric statistics. Univariate and bivariate analyses were conducted. The latter included cross tabulations, Chi-squared tests, and Kruskal-Wallis for $k$ independent samples to compare responses to individual questions in the patient views questionnaire about appetite, food choice, environment and nutritional support at baseline, interim and the end of the project.

A scoring system for the staff questionnaires was agreed on by the project team. Some items included more than one

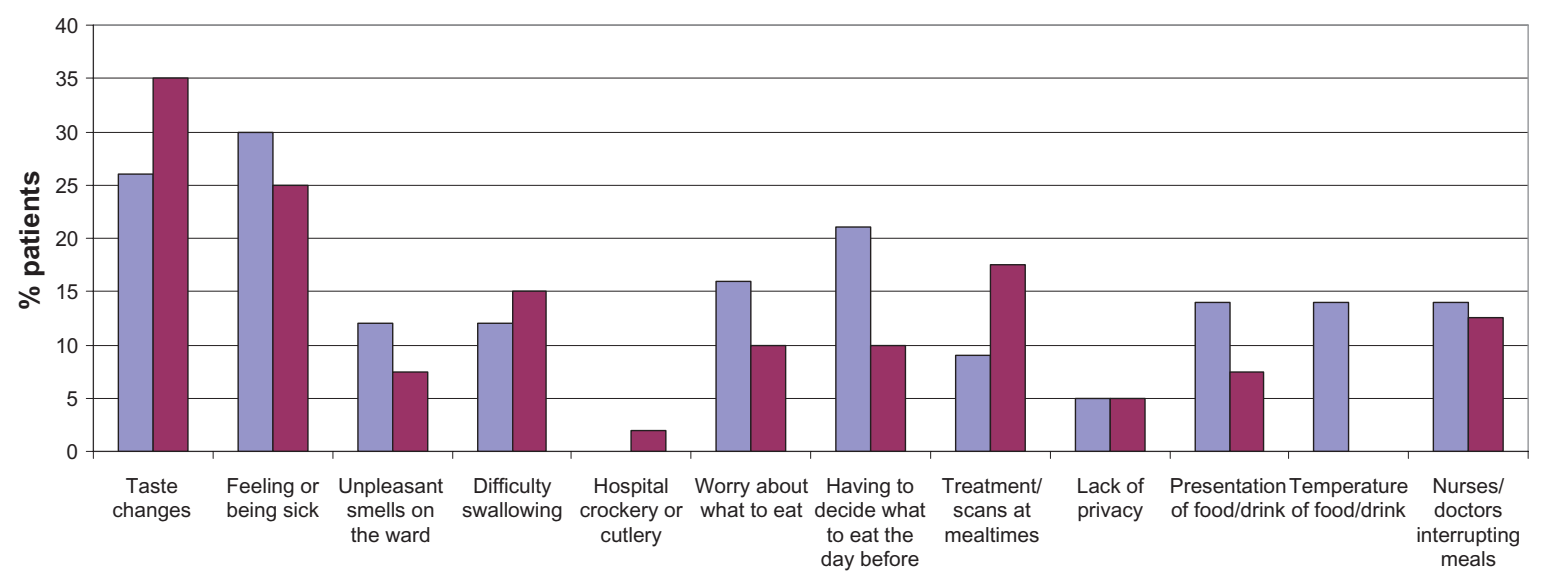

Baseline $\square$ End of project

Figure I Issues reported as either most likely or equally likely to interfere with eating and drinking on the ward. 
Table I Nutritional problems reported to the nutritional care assistant for the 277 patients seen over the duration of the project

\begin{tabular}{ll}
\hline Nutritional problems & $\mathbf{N}(\%)$ \\
\hline Recent changes in taste and smell & $113(40.8)$ \\
Recent change in appetite & $211(76.2 \%)$ \\
Recent weight change & $183(66.1 \%)$ \\
Difficulty chewing or swallowing & $65(23.5 \%)$ \\
Change in bowel habits & $46(16.6 \%)$ \\
Nausea or vomiting & $86(31.0 \%)$ \\
Allergies or food intolerance & $7(2.5 \%)$ \\
\hline
\end{tabular}

correct answer, so individual points were given for each correct response. A maximum of 36 points could be awarded for the complete questionnaire. Total scores were calculated for each staff member and a percentage score allocated. Because these were cross-sectional data, baseline and end of project responses to the staff questionnaires were compared using Mann-Whitney U tests.

Open-ended responses from patient and staff questionnaires were transcribed verbatim and used to illustrate the range and diversity of feedback received.

\section{Results}

\section{Number and characteristics of patients seen by the NCA}

During the 22 months of the project in which the nutritional care service was fully operational, $n=9920$ patients were admitted to the oncology ward. Smoothies and fruit were offered each day to all patients on the ward during the working week (Monday to Friday). Any patients who were recorded by ward nursing staff on initial screening as being at medium or high risk of malnutrition, were referred to the NCA. Each of these patients underwent a more detailed assessment to determine their particular nutritional problems, so as to guide the most appropriate nutritional care. On occasions, patients who were recorded as low risk were also referred to the NCA, if they had particular questions or concerns about eating or drinking.

Between August 2004 and April 2006, 277 patients were assessed individually by the NCA. The number of patients seen rose fairly steadily over the duration of the project, with an average of 11 patients seen per month in the first 6 months to an average of 18 patients seen per month in the second 6 months. The overall project average per month was 14 patients.

Of the 277 patients seen during the project, 124 were men and 153 were women. Their ages ranged from 24 to 95, with a median age of 67 . Unfortunately, the nutritional risk scores of 44 patients were missing from project documentation. Of the remaining 233, 137 (59\%) were medium risk, 73 high risk (31\%), and 23 low risk (10\%). Fifty-three out of 277 (19\%) were referred to the dietitian.

The most common problems recorded were recent changes in appetite, weight loss and changes in taste or smell. Results are displayed in Table 1.

\section{Nutritional screening procedures}

At baseline, 25 sets of patients' notes were audited to assess how well nutritional status was being documented routinely. At the end of the project, 34 sets of patients' notes were audited. Although sample sizes were small and patients' notes were selected to give a snapshot rather than a representative

Table 2 Mean scores related to statements about food choice, environment and nutritional support

\begin{tabular}{|c|c|c|c|}
\hline Statement & $\begin{array}{l}\text { Mean baseline } \\
\text { score }(95 \% \mathrm{CI})\end{array}$ & $\begin{array}{l}\text { Mean final } \\
\text { score }(95 \% \mathrm{CI})\end{array}$ & $P$ value \\
\hline I am offered food and drink at times & 3.42 & 3.81 & 0.002 \\
\hline that suit me & $(3.04-3.79)$ & $(3.34-4.28)$ & \\
\hline There is enough variety to enable me to & 3.36 & 3.85 & 0.144 (NS) \\
\hline choose meals/drinks I feel like eating & $(2.93-3.79)$ & $(3.38-4.31)$ & \\
\hline "There are too many distractions for me & 2.75 & 2.27 & 0.26 (NS) \\
\hline to enjoy my meals & $(2.33-3.17)$ & $(1.83-2.7 I)$ & \\
\hline Meals and drinks are left & 4.14 & 3.92 & 0.393 (NS) \\
\hline within my reach & $(3.85-4.43)$ & $(3.45-4.39)$ & \\
\hline Staff are helpful in providing food/drinks & 3.72 & 4.08 & 0.022 \\
\hline which I like to eat or drink & $(3.36-4.08)$ & $(3.68-4.47)$ & \\
\hline Staff are able to give me the information & 3.75 & 4.31 & 0.014 \\
\hline I want about eating and drinking & $(3.43-4.07)$ & $(3.93-4.68)$ & \\
\hline I feel that the staff on the ward care about & 3.92 & 3.96 & 0.329 (NS) \\
\hline what I am eating and drinking & $(3.63-4.20)$ & $(3.6 I-4.3 I)$ & \\
\hline I often receive food and drinks that & 3.14 & 2.58 & 0.0001 \\
\hline I do not want & $(2.60-3.68)$ & $(2.05-3.1)$ & \\
\hline
\end{tabular}


view, the results of the audit suggest that the documentation of nutritional status improved considerably during the project.

\section{Documentation of weight, height}

\section{and body mass index (BMI) in nursing notes}

At baseline, only 7 out of 25 (28\%) patients had their weight measured and documented in their nursing notes, but by the time of the end of project audit, 30 out of $34(88 \%)$ had a recorded weight. $100 \%$ of those weighed at the end of project audit had been weighed within a week of admission, compared with only $20 \%$ at baseline.

Documentation of height and BMI also improved, although less markedly. At the end of project audit, 50\% had a documented BMI compared with only $12 \%$ at baseline and $67 \%$ had their height documented, compared with $42 \%$ at baseline. Half the patients at the end of project audit had their percentage weight change recorded, compared with a very small minority $(8 \%)$ at baseline.

Nutritional screening tools appeared to be more available and more likely to be completed at the end of the project, due to the introduction of the MUST ${ }^{8}$ tool into routine clinical practice. Seventeen out of 30 patients (57\%), for whom a MUST screening tool was available at the end of the project, had their screening assessment completed, compared with only $12 \%$ at baseline. It must be noted that the guidelines which came into use during the project made it a requirement that all in-patients were screened for nutritional risk, therefore it is quite possible that improvements in screening may have occurred anyway. ${ }^{18}$ Before these guidelines were introduced, a nutritional screening tool ${ }^{20}$ was available on the ward, but it was not widely used.

\section{Documentation of food preferences in nursing notes}

At the end of project audit, nearly all patients had the following aspects of their nutritional status recorded by nursing staff - likes and dislikes (food and fluid), preferred eating and drinking times, social/cultural needs, environmental preferences at mealtimes, and physical or mental factors likely to interfere with eating and drinking. In contrast, none of these were recorded more than a few times at baseline.

\section{Patients' views about eating and drinking on the ward}

\section{Eating and drinking questionnaires}

The patient views questionnaire was completed by 41 patients and two carers at baseline; 43 at the interim evaluation and 40 at the end of the project. Frequencies were calculated to compare the aspects that most interfered with patients' enjoyment of eating and drinking at each time point. Taste changes and feeling, or being, sick were scored as most likely to interfere with eating and drinking. Figure 1 shows the percentage of patients who rated each problem as either most important or equally important as the other problems.

There were a number of encouraging, and statistically significant, trends in response to questions about appetite, food choice, environment, and nutritional support, suggesting that overall, patients' experiences of eating and drinking improved over the duration of the project. Patients were asked how their appetite compared with that at home, and at each successive evaluation time point, fewer patients reported that it was worse in hospital (23\% at baseline compared with $17 \%$ at the final time point), and more reported that it was better ( $21 \%$ at baseline compared with $28 \%$ at the final time point) (chi sq. $P=0.026$ ).

The number of patients who said they were eating little (as opposed to most or all) of their hospital food (including supplements and snacks) fell from $23(53 \%)$ at baseline to $11(27 \%)$ at the end of the project $(P=0.007)$. A greater proportion of patients reported that portion sizes were just right (78\%) than had been the case at baseline (63\%). However, more patients at the end of the project reported that drinks were too cold ( $26 \%$ compared with $16 \%$ at baseline).

Table 3 Comments from patients about the service provided by the nutritional care assistant

I remember when I couldn't face food and meals your smoothies and fruit got me through a time when I felt terrible... please keep this going. Psychologically makes a difference.

When not eating due to loss of appetite I found the fruit and smoothies easier to take.

Appetite down and when you see them [fruit and smoothies] presented it boosts your appetite.

I looked forward to the fresh fruit every afternoon, so nicely prepared by a caring member of staff.

Nothing was ever any trouble. Help with meal consistency and menu was much appreciated as I have very poor eyesight.

A wonderful idea, I so looked forward to it.

Passes time nicely. Lifts you up.

The smoothies, fruit are a welcome addition and seem very fresh much fresher/healthier obviously than mainstream food.

Very refreshing and I would miss it if it was stopped.

Feeling sick and not able to stomach meal - greatly enjoyed the cut up fruit each day.

Easy to eat foods are ideal if you don't feel like a main course.

The fresh fruit was lovely and so attractive and colourful on the serving plate. It was very tasty and I hope it will continue.

The hospital food is quite adequate but perhaps some thought should be given to people with reduced appetite. I think this is where the service provided by the NCA makes a difference. 
Responses to the Likert style questions illustrated that patients' experiences of all aspects of eating and drinking improved over the duration of the project. Significant differences were found in a number of areas, and overall the trend was towards a more positive experience, as shown in Table 2.

For most items in Table 2, favorable responses are associated with a score above $3(3=$ neither sure or unsure, $4=$ agree, $5=$ strongly agree). Those items marked ${ }^{*}$ are negatively worded, therefore a more favorable response is associated with a lower score $(1=$ strongly disagree, $2=$ disagree).

\section{Snack questionnaires}

Eighty patients completed the short questionnaire assessing views of the fruit, snacks, and smoothies provided by the NCA project. Thirty-two men and 43 women completed questionnaires (NB five people did not state their sex). Nearly half $(\mathrm{n}=35)$ were over 65 years old, and 25 were under 65 (NB 20 did not complete this question).

Seventy (87.5\%) patients said they had been offered a smoothie or build up drink between meals, 63 (79\%) had been offered fresh fruit, and 57 (71\%) a dessert or yoghurt, high energy snack such as pancake, or a savory snack. Fifty patients $(62.5 \%)$ said they had been given something they had not tried before (mostly smoothies), and 59 (74\%) said they would try these again at home.

When asked to rate, on a 4 point Likert scale, how much difference (if any) the snacks, smoothies, and fruit had made to the comfort or enjoyment of their hospital stay, the vast majority $(n=40 ; 81 \%)$ felt that it had a great deal or quite a difference as the results in Figure 2 show.

Patients were given the opportunity to comment about their snacks, fruit and smoothies, as well as their experience of the NCA service and the hospital food in general.

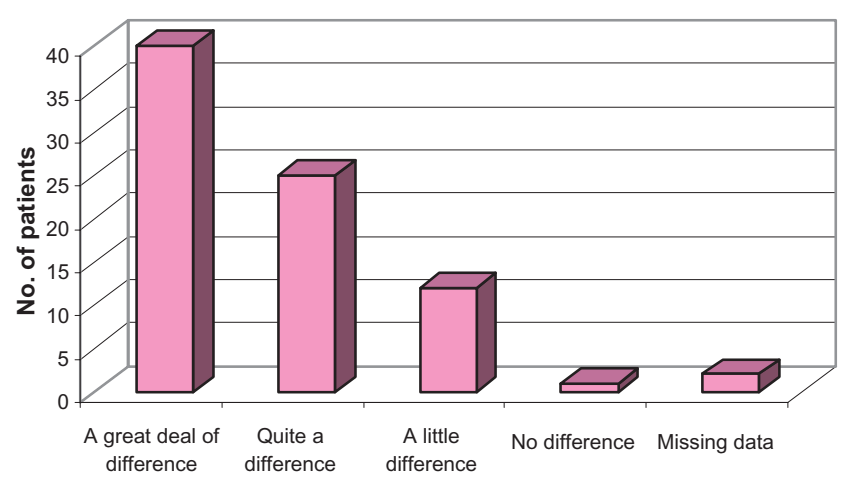

Figure 2 Patients' ratings of the difference that snacks, fruit and smoothies made to their comfort and enjoyment during their hospital stay.
Almost all patients commented positively, and their words are a powerful illustration of the difference the NCA service made to their experience of being in hospital (see Table 3 for selected comments). Only two people commented that the smoothies were too creamy and too sweet for their tastes. A few made general suggestions for improving hospital food and drink including changing the menu more often, improving the taste of the water, and providing a glass of wine!

\section{Staff knowledge and skills}

Twenty-five staff completed a nutrition questionnaire at baseline and 23 at the end of the project. Because questionnaires were anonymous, we could not compare changes in individual scores over time. The results of the staff questionnaires therefore provide an overall impression of nurses' nutritional knowledge and give a flavor of some of the misconceptions held by nurses about nutrition, but cannot be assumed to provide a comprehensive assessment of whether or not the NCA project specifically had an impact on knowledge and skills. Summary scores are provided in Table 4.

Although Table 4 shows that total scores were higher at the end of the project, this difference was not significant ( $P=0.154$ using Mann-Whitney test). An analysis of individual items on the staff quiz was also conducted to assess knowledge and skills in relation to specific items. Overall, the staff questionnaire identified that nurses lacked practical knowledge and skills about nutrition. The results did not suggest that the NCA project had much impact on staff knowledge and skills. It must be recognized that the items included on the questionnaire were not validated and that several had a number of possible answers rather than a right

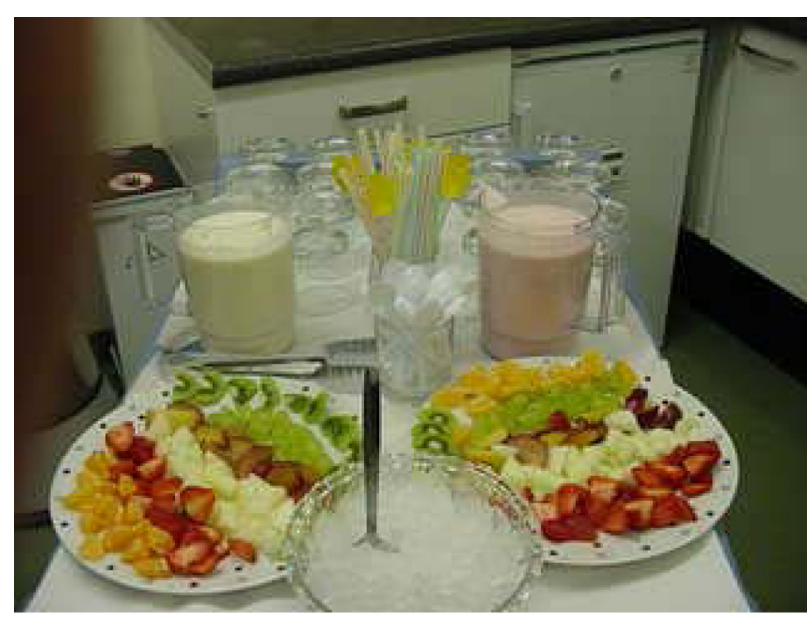

Figure 3 Daily smoothies and fruit round, as provided by the nutritional care assistant. 
Table 4 Summary scores of nursing staff for nutrition quiz conducted at baseline and end of project

\begin{tabular}{llll}
\hline & Staff nurse & $\begin{array}{l}\text { Health care } \\
\text { assistant }\end{array}$ & All staff \\
\hline $\begin{array}{l}\text { No. of staff completing } \\
\text { questionnaires at baseline }\end{array}$ & 19 & 6 & 25 \\
$\begin{array}{l}\text { No. of staff completing } \\
\text { questionnaires at end of project }\end{array}$ & 18 & 5 & 23 \\
$\begin{array}{l}\text { Mean baseline score }(95 \% \mathrm{Cl}) \\
\text { Range }\end{array}$ & 22.6 & 21.4 & $22.3(20.6-24.1)$ \\
$\%$ score & & & $15-28$ \\
$\begin{array}{l}\text { Mean end project score }(95 \% \mathrm{Cl}) \\
\text { Range }\end{array}$ & $63 \%$ & $59 \%$ & $62 \%$ \\
\% score & 24.6 & 22.7 & $24(22.2-25.8)$ \\
& $68 \%$ & $63 \%$ & $17-30$ \\
\end{tabular}

or wrong answer. The anonymous nature of the questionnaire also limited the extent to which actual changes in knowledge could be assessed.

However, verbatim comments provided by staff at the end of the project suggested that they perceived a number of benefits, including improved choice and enjoyment of food for patients, availability of advice on diet and nutrition, improved nutritional assessment and prioritization, better use of resources, greater awareness and education amongst patients, carers and staff, in relation to nutrition. Many staff commented on the very positive feedback they had received about the NCA service from patients and carers on the ward. In addition, observations of care conducted by the senior charge nurse on the ward suggested that nutrition was being given a higher priority on the ward, and that nursing staff were now taking more of an interest in nutritional care, discussing different ideas and options for patients' nutrition more openly than they were before the project. During the project, 19 members of staff participated in education and training events related to nutrition, and three health care assistants were trained to assist the NCA with nutritional assessment and individualized nutritional care at ward level.

\section{Discussion}

The NCA project helped to make a number of important changes to the way in which the nutritional needs of patients with cancer were addressed on the oncology ward. The evaluation provided qualitative and quantitative evidence that standards of care improved in relation to the following key aspects of nutrition:

- individualized nutritional care and support with meal planning and consumption for 277 patients, the majority of whom were screened as medium or high risk

- patient information and advice about nutrition

- patient enjoyment and comfort of staying in hospital
- food choice and availability at ward level

- nutritional screening and documentation

- staff attitudes and awareness of nutritional needs

Anecdotal reports from patients, doctors, nurses and dietitians supported the results of the evaluation, showing that the NCA service and the smoothie, snack, and fruit rounds in particular, were seen to enhance the quality of patients' stays in hospital during a difficult time in their lives.

Overall, the project made a number of tangible changes to the provision of food and drink on the ward. Before the introduction of the nutritional care service, patients were provided with three meals a day from the hospital trolley, tea or coffee with a plain biscuit between meals, and a milky drink at bedtime. The NCA project enabled all patients to be offered a glass of fresh fruit smoothie (made with cream, ice cream or yoghurt for extra energy) and a bowl of fresh fruit salad each afternoon, in addition to the usual drinks service. Morning coffee rounds extended to include snacks such as pancakes, gingerbread, muffins, or cakes. Patients requiring extra calories were offered hot drinks made with milk rather than water. Other snacks such as ice creams and ice lollies were also provided as an alternative in hot weather. The project also enabled a ward stock of tinned fruit, soup, baked beans, macaroni cheese, and other light meals to be maintained for patients who required extra calories. Puddings such as custard, rice pudding, or yoghurt were also available. Sweet and savory drinks and snacks could therefore be selected according to patients' needs and preferences.

Observations by health care assistants, nurses and dietitians indicated that the smoothie, fruit, and snack rounds often initiated conversations, laughter and a sense of camaraderie between patients, as they chatted about the food and drink that was on offer. This appeared to encourage some of the social and everyday aspects of eating and drinking to emerge, in an environment that is often at odds with normal life. 
Having a designated person to focus on nutritional care at ward level appeared to be a very useful strategy in promoting positive change. Other studies have also found that good nutritional care is dependent on care staff who are committed to, and take responsibility for, food and drink provision, who are able to liaise with hospital kitchens, and provide individualized advice and support to patients at ward level. ${ }^{21,22}$ However, getting staff on board with the project was a significant challenge and the enthusiasm of staff to incorporate a greater focus on nutritional care into their daily working routines was initially overestimated. Although the appointment of a designated NCA was integral to the initiation and development of the service, it also set the NCA apart from the rest of the ward team. This resulted in some difficulties with acceptance of the role, integration as a member of the ward team, and delegation of NCA duties. Many of these problems improved over time, but must be considered by teams who are contemplating such a change in service. The support and contribution of the project and ward dietitians was also crucial to the success of the service. A productive working relationship between the ward nurses, $\mathrm{NCA}$, and dietitian is fundamental to enhancing standards of nutritional care.

This audit showed that developing a nutritional care service on one ward within a large NHS hospital is challenging, but possible. A number of practical and logistical hurdles had to be overcome in order to provide snacks at ward level, including health and safety, infection control, food supply, food storage, and funding for snacks and drinks. For instance, it proved impossible to order a wide range of inexpensive and healthy snacks directly through the NHS in quantities that could be stored at ward level, so it was necessary to shop outside the hospital.

The project coincided with significant activity within the NHS to implement the QIS (Quality Improvement Scotland) standards for Food, Fluid and Nutritional $\mathrm{Care}^{18}$ in Tayside. Several members of the project group were involved in this work, and the ward was used as an example of good practice in nutritional care. Experiences and insights gained from the NCA project have since been used to inform the development of new nursing documentation and policies for nutritional care across the hospital, including the "red tray initiative" - a means of highlighting which patients require individual assistance with meals. ${ }^{23}$ Additionally, the project provided a springboard for other role developments (eg, chemotherapy care) for health care assistants in oncology. The positive effects of working with a ward team to initiate a change in care, and conduct a concurrent evaluation of that change, have been documented by others. An action research study conducted on a 'care of the elderly ward' illustrated the benefits of involving ward staff in a nutritional care project, both on patients' experiences of mealtimes and on nursing care overall. ${ }^{24}$

The methods used to evaluate the NCA project have provided useful and comprehensive snapshot data on a range of outcomes. There were a number of limitations to this audit, however. The sample of patients completing questionnaires was relatively small and cross-sectional. We did not perform a sample size calculation, so it is possible that the study was underpowered to detect changes. Unfortunately, the small evaluation budget did not allow evaluation of the impact of the project on individuals' nutritional status. Similarly, NHS systems to monitor food wastage were insufficiently detailed to illustrate whether the project had any effect on the number of meals or supplements discarded or sent back to the kitchen. However, there were suggestions that the project resulted in more efficient use of oral nutritional supplements, and more appropriate referrals to dietetic services. This is important, given that one of the most common methods of treating malnutrition in hospital is the use of oral nutritional supplement drinks, ${ }^{6}$ and that an audit of nutritional supplement consumption on a 'care of the elderly ward' found that only $43 \%$ of prescribed supplement drinks were actually consumed by patients. ${ }^{25}$

Other studies have shown that nutritional counseling and advice is an effective means of maintaining nutritional status, avoiding excessive weight loss, and promoting quality of life and satisfaction in cancer patients. ${ }^{19,26}$ The potential for health care assistants to provide nutritional advice and support is increasingly being investigated. Although an early UK study ${ }^{27}$ found that health care assistants trained in nutritional care had no impact on length of stay, nutritional status (other than less requirement for intravenous antibiotics) or mortality of acutely ill elderly patients, other studies have found that employing dietetic assistants or even volunteers, has led to considerable benefits. One randomized trial of the effectiveness of dietetic assistants on the nutritional status of elderly women with hip fracture found that dietetic assistants-supported participants were less likely to die, had significantly better mean daily energy intake, significantly smaller reduction in mid-arm circumference during their inpatient stay and favorable, albeit statistically non-significant results for other anthropometric and laboratory measurements. ${ }^{28}$ Although the NCA project had a positive impact on nutritional care, further research needs to be conducted on the effect of nutritional care assistants on a range of clinical outcomes in patients with cancer. 


\section{Conclusion}

The NCA project was able to make a tangible difference to standards of nutritional care on an adult cancer ward, and also provided a catalyst for change across the hospital. It is clear that nutritional care needs a whole system approach, and that relatively simple changes at ward level, such as those incorporated within the NCA service, can make a significant difference to patients with cancer whilst they are in hospital.

\section{Acknowledgments}

The authors wish to thank Evelyn Philip (NCA) for her hard work and dedication; Alison Marshall, Mhairi Mitchell, Sue Kilby, and Janet Baxter for dietetic input, advice and commitment; Rhian Baxter, Amanda Degabriele, and Preye Kagbala for assistance with the project; and Mel, Kay, Sandra, and Irene for their willingness and enthusiasm to take on the nutritional care of patients on the ward after completion of the project.

\section{Disclosure}

The authors declare no conflicts of interest.

\section{References}

1. McWhirter J, Pennington C. Incidence and recognition of malnutrition in hospitals. BMJ. 1994;308:945-948.

2. Poole K, Froggatt K. Weight Loss in Advanced Cancer: A Literature Review. London: Macmillan Cancer Relief; 2002.

3. Argiles J. Cancer-associated malnutrition. Eur J Oncol Nurs. 2005;9:S39-S50.

4. Persson C, Johansson B, Sjöden P, Glimelius B. A randomized study of nutritional support in patients with colorectal and gastric cancer. Nutr Cancer. 2002;42:48-58.

5. Andreyev H, Norman A, Oates J, Cunningham D. Why do patients with weight loss have a worse outcome when undergoing chemotherapy for gastrointestinal malignancies? Eur J Cancer. 1998;34:503-509.

6. Stratton R, Green C, Elia M. Disease-Related Malnutrition:An EvidenceBased Approach to Treatment. Wallingford: CABI Publishing; 2003.

7. Ross P, Ashley S, Norton A, et al. Do patients with weight loss have a worse outcome when undergoing chemotherapy for lung cancers? $\mathrm{Br} \mathrm{J}$ Cancer. 2004;90:1905-1911.

8. Elia M. Guidelines for detection and management of malnutrition. Maidenhead: Malnutrition Advisory Group (MAG), Standing Committee of BAPEN; 2002.

9. Age Concern. Hungry to be heard. The scandal of malnourished older people in hospital. London: Age Concern; 2006. http://www.ageconcern. org.uk/AgeConcern/Documents/Hungry_to_be_Heard_August_ 2006.pdf

\section{Clinical Audit}

\section{Publish your work in this journal}

Clinical Audit is an international, peer-reviewed, open access journal focusing on the processes and outcomes of clinical audit in any area of healthcare. All aspects of patient care are addressed within the journal and practitioners from all disciplines are invited to submit their work. Areas covered include: Publication of audits; How an audit has changed practice;

Submit your manuscript here: http://www.dovepress.com/clinical-audit-journal
10. Savage J, Scott C. Patients' Nutritional Care in Hospital: An Ethnographic Study of Nurses' role and patients' Experience. London: Royal College of Nursing Institute; 2005.

11. Barton A, Beigg C, Macdonald I, Allison S. High food wastage and low nutritional intakes in hospital patients. Clin Nutr. 2000;19:445-449.

12. Jordan S, Snow D, Hayes D, Williams A. Introducing a nutrition screening tool: an exploratory study in a district general hospital. $J A d v$ Nurs. 2003;44:12-23.

13. Van Cutsem E, Arends J. The causes and consequences of cancerassociated malnutrition. Eur J Oncol Nurs. 2005;9:S51-S63.

14. Warnock C, Tod A, Kirshbaum M, Powell C, Sharman D. A pilot study examining nutrition and cancer patients: Factors influencing oncology patients receiving nutrition in an acute cancer unit. Eur J Oncol Nurs. 2006;9:197-201.

15. Davies M. Nutritional screening and assessment in cancer-associated malnutrition. Eur J Oncol Nurs. 2005;9:S64-S73.

16. Barton A, Beigg C, Macdonald I, Allison S. A recipe for improving food intakes in elderly hospitalized patients. Clin Nutr. 2000;19:451-454.

17. Price R, McMurdo M, Anderson A. A personalized snack-based intervention for hip fracture patients: development, feasibility and acceptability. J Hum Nutr Diet. 2006;19:139-145.

18. NHS Quality Improvement Scotland. Food, Fluid and Nutritional Care in Hospitals. Edinburgh: NHS Quality Improvement Scotland; 2003.

19. Isenring E, Capra S, Bauer J. Patient satisfaction is rated higher by radiation oncology outpatients receiving nutrition intervention compared with usual care. J Hum Nutr Diet. 2004;17:145-152.

20. Reilly H. Symposium on 'Nutrition in clinical management: malnutrition in our midst'. Proc Nutr Soc. 1996;55:841-853.

21. Lassen K, Olsen J, Grinderslev E, Kruse F, Bjerrum M. Nutritional care of medical inpatients: a health technology assessment. BMC Health Services Research. 2006;6.

22. Warnock C, Tod A, Kirshbaum M, Powell C, Sharman D. A pilot study examining nutrition and cancer patients: Factors influencing oncology patients receiving nutrition in an acute cancer unit. Clin Eff Nurs. 2005;9:197-201.

23. Bradley L, Rees C. Reducing nutritional risk in hospital: the red tray. Nurs Stand. 2003;17:33-37.

24. Dickinson A, Welch C, Ager L. No longer hungry in hospital: improving the hospital mealtime experience for older people through action research. J Clin Nurs. 2008;17:1492-1502.

25. Ross F. An audit of nutritional supplement distribution and consumption on a care of the elderly ward. J Hum Nutr Diet. 1999;12:445-452.

26. Ravasco P, Monteiro-Grillo I, Camilo M. Does nutrition influence quality of life in cancer patients undergoing radiotherapy? Radiother Oncol. 2003;67:213-220.

27. Hickson M, Bulpitt C, Nunes M, et al Does additional feeding support provided by health care assistants improve nutritional status and outcome in acutely ill older in-patients? A randomised control trial. Clin Nutr. 2004;23:69-77.

28. Duncan D, Beck S, Hood K, Johansen A. Using dietetic assistants to improve the outcome of hip fracture: a randomised controlled trial of nutritional support in an acute trauma ward. Age Ageing. 2006;35: $148-153$.

\section{Dovepress}

Practical tips on how to do audits and to avoid pitfalls; How audits have changed patient care; Calls and justifications for new audits. The manuscript management system is completely online and includes a very quick and fair peer-review system, which is all easy to use. Visit http://www.dovepress. com/testimonials.php to read real quotes from published authors. 